\title{
Educational Technology and Educational Management in the Higher Education: New Ways of Forming Professionals
}

\author{
Naura S. C. Ferreira1, Monaliza E. O. Haddad², Adriano A. Faria ${ }^{3}$ \\ ${ }^{1}$ Master and Doctorate Degrees in Education, Tuiuti University of Paraná, Curitiba, Brazil \\ ${ }^{2}$ Learning and Development Institute, Araucária, Brazil \\ ${ }^{3}$ Doctoral Program in Education, Tuiuti University of Paraná, Curitiba, Brazil \\ Email: nauraf@uol.com.br, monalizahaddad@uol.com.br, adriano@edusol.org.br
}

Received September 2013

\begin{abstract}
Discussing the importance of Educational Technologies is essential for building the Educational Management in the Higher Education since it has a strong indication on the necessity of discussing problems that involve the scientific-technological context and the social context. Aiming to understand how the educational practice is dealt with and how it can add valuable contributions to the challenge of searching for knowledge. With this premise, we present the problem: How should we use the Information and Communication Technologies in Education for the Higher Education? What is the role of the teacher in the Higher Education and how his/her networking discourse contributes to create more symmetrical relations than the ones we have in a traditional educational context? Is the use of Information and Communication Technologies able to establish a new way of coexisting with a world that strives to become more human, demanding new means of intervention to humanize the relations? With these questions in mind, we developed a research with the objective of analyzing the usage of educational technology in the Higher Education. Nowadays, the Educational Technology has to be thought, learned and used as a resource and a mean to qualify and humanize everyone. This research was carried out through considerations and investigations on the Research Line of "Public Policies and Educational Management" of the Post-Graduation program in Education of the Tuiuti University of Paraná/Brazil. From this research, we could infer that using the Information and Communication Technologies in Education as a pedagogical resource is necessary as a valuable "support" in forming the creative and critical thought when the apprentice takes ownership of the theoretical-methodological and ethical-political basic principles of Information and Communication Technology.
\end{abstract}

\section{Keywords}

Education; Higher Education; Information and Communication Technologies; Pedagogical Resource 


\section{Introduction}

The real changes that occurred in the world of work and in the social relations as well as the science and technologies advances at the age of globalization, and the so called "Knowledge Society", demand a thorough examination of the decisive role that Educational Technology plays in the Higher Education while forming qualified and capable professionals for the professional practice and for displaying social responsibility. It also demands the examination of the responsibilities and possibilities of applying the technology, the risks and challenges brought by this reality and the investigation on overcoming the risks, comprehending the need of ideas, contents and values systematization as well as its appropriate use in Higher Education.

This project presents considerations developed from the research in the Research Line of "Public Policies and Educational Management" of the Post-Graduation program in Education of the Tuiuti University of Paraná/ Brazil. These considerations aim to: a) use the Educational Technologies of Information and Communication in Higher Education as a pedagogical resource that promotes in the student a conscience regarding these resources; b) the role of teachers in Higher Education and their networking discourse contributing in the creation of more symmetrical relations than the ones we have in a traditional educational context; c) the usage of Information and Communication Technologies establishes a new way of coexisting with a world that strives to become more human, demanding new means of intervention to create more humanized relations.

To investigate is to consider that the human formation of professionals of education, or any other professional or even regular citizens, needs to incorporate all scientific and technological progress developed by men for the good of all human kind.

\section{A Contradictory Reality}

The most remarkable characteristic of the working world in the beginning of this century is the global aspect. At the same time that the Capitalism globalization occurs, "even considered as a civilizing process" [1], the world of work globalization takes place. Within the scope of the global factory shaped under the new international division of labor and production, that is the transition from Fordism to Toyotism and the dynamics of the world market extensively favored by the electronic technology, new forms and meanings of work demand new ways of comprehending and new competences regarding the usage and the decisive role of Educational technology on forming not only new capable professionals but also social responsible citizens. The "Knowledge Society" enables the human being to "go forward" and become "astonished" with the possibilities of "going forward", even with all the contradictories contributions.

This way, economy globalization and productive restructuration, the macro strategic components that set the flexible accumulation, establish a new model of economical "development" that in the last decades [2] have leveraged the role of Knowledge as a protagonist.

The growing integration of science and technology to the productive and social processes, working for the internationalized capital accumulation process, sets an apparent contradiction: the more the tasks are simplified, the more will be the knowledge required from the worker, and therefore expanding their education to the Continuing Education.

The connection between education and work is now seen through the amount of knowledge and higher cognitive skills, since the Taylorism/Fordism and its different ways of having the work done, be it through physical strength, hands or specific abilities that demanded fine coordination and visual acuity.

Changes from electronics to microelectronics bases, or from rigid procedures to flexible ones have reached all areas of social and productive life. In the last decades, it has become essential the improvement of cognitive and behavioral capabilities such as analysis, synthesis, forming relations, responsiveness and creativity facing unknown situations, clear and accurate communication, interpretation and use of different forms of language, ability to work in groups, process management, determining priorities, criticizing answers, validating procedures, pressure endurance, facing permanent changes, allying logical reasoning to creative intuition and continuously studying [3].

Rapid changes have profoundly affected the men, the environment and social institutions. Especially these suffer a huge impact caused by the use of new technologies that, usually, change habits, values and traditions that seemed unchangeable [4]. 
Within this context, institutions, such as universities, are challenged to follow and adapt to environmental changes provoked by the application of new technologies usually implemented by the private sector, and they are challenged to produce technologies that will guarantee their graduates the abilities to an excellent professsional performance.

This new reality requires higher qualifications in any professional area or service, making educational needs each time bigger. Those who do not follow technological changes are prematurely inept for work.

All those transformations happen so fast, and they have changed, at the same speed, all determinations in the world, such as the violence, a determinant element during diurnal life. As the ICT (Information and Communication Technology) has given so much rapidity to all human kind, everyone's frame reference has changed. Everyone lives, feels, thinks and acts in high speed, violently, disrespecting all human forms of labor and social coexistence. We live under the violence of communication speed; we live under the violence caused by the transnationality of thinking, feeling and acting from all cultures, shaking those very cultural and their local social values, "transmuting" the traditional forms of existence production and social organization. We live at a time when "everything happens because everything is allowed and does not have any value anymore". Everything is allowed! Within this amorality, violence takes place in its most degrading forms, affecting not only individuals but families, social institutions and nations.

This new international setting that intensifies the violence as something regular, demands from us rethinking about modernity in its philosophical, scientific and artistic implications as well as rethinking citizen and professsional's formation. It is also necessary to examine the responsibilities and possibilities of technology employment within the purpose for what it has been created, and this means a resource and instrument to personal qualification, for the good of human kind.

It is necessary to examine the risks and challenges that we face with this new reality to conceive and plan more committed ways to build a fairer and humanized world. It is also necessary to examine how to overcome the risks effectively using ideas, contents and values systematization.

The contradictory reality, with all scientific and technological growth at the same time, present us with all possibilities of living and it forces us with all forms of competitive individualism that awakes the rivalry, hate, revenge and many other wicked feelings.

As an example we have the television that, paradoxically, has the power to conceal at the same time that shows, to inform in a way that goes inadvertently or that seems insignificant, or even to elaborate the information, so it takes a completely different meaning from reality, it has the power to mask the reality according to the interests of those who own the channel.

Journalists have particular "lenses" through which they see some things and do not see others, and what

they see, they perceive it in a special way. They select and soon elaborate on what they have selected [5].

And, in this dis(order) of things that we live nowadays, children, teenagers, adults and elderly, professionals and "people with no jobs" also live with information and marketing "bombing" stunning minds and shuffling thoughts, feelings and actions, leading to chaos of "fantasies" and contradictorily, "illusions", "hopes" and "hopelessness".

It is important not only to collect information, but to know how to process all those information critically, preparing for the true freedom exercise that is only possible to achieve through critical knowledge. By doing it, people will be free because they will know how to choose; and they will be able to choose only when they critically understand the alternatives because without options, there is no freedom; and without analysis, the freedom exercise is not really available. In order to achieve that, it is necessary to know how to believe and how to suspect and mainly how to investigate reality.

\section{The Use of Information and Communication Technologies in Education as a Pedagogical Resource}

Educational Technology in Higher Education needs to be aware about the theoretical comprehension of the teaching methodologies in relation to the global social practices, but also considering the evaluation of communication theories and the development of new cutting-edge technologies. For this, it must be considered the information and communication technologies as a pedagogical resource, by using them inside schools and universities in a scientific and critical way or by putting its critical power into practice in order to analyze the existent 
issues and, also, study it with colleagues and students, intending to offer new alternatives and more conscious possibilities for interpretation and decision making.

The Educational Technology is understood as a knowledge corpus that, basing upon scientific subjects that focus the teaching practices, incorporates all the means as possible and gives answers for the accomplishments of the social-historical contexts that give significance, assuming another meaning in the contemporaneity [6].

The current discussions about educational technology may strengthen the ideological-political and ethicalphilosophical concerns such as criticism and overcome the technicality marks that were developed in the formation of citizens and professionals in the last decades in Brazil. By analyzing the historical point of view, for a long period the definition of the educational technology was combined to technocratic purposes that diminished the human beings and their professional formation downward into a mere training of "neutral" competences that "molded" them as someone abstracted of the real social and human issues.

The technology not only allows acting on the nature, and should, but also mainly permits thinking about it. Differently from what was conceived during the technicality period, the educational technology needs to be thought, learned and used nowadays as a resource to qualify people, aiming to overcome the violence that destroys the humanity. According to it and making critics regarding the overcoming process, [7] affirmed that this kind of power is immeasurable since it possesses all the special effects in the most different ways of its production and that, because of it, seduces and "creates" opinions and minds according to "mercantile interests", "audience interests" or "wicked interests" without respecting and preserving the different ages. It "orientates", but at the same moment disorientates, people into the most chaotic directions.

It is up to the school and education the act of assuming the role and the real responsibility to learn and manage technologies, on both the information and the communication, presupposing to clarify and help to perceive the essential and the superfluous. With this in mind, it is important to enable the most conscious and wisest decision-making, establishing communication processes even more participative and richer in the daily construction of a more humanized, worthiest and happiest life.

The usage of information and communication technologies in education as a pedagogical resource in not only necessary but it is a valuable "support" for the formation of critical and creative thoughts when the apprentice takes ownership of the theoretical-methodological and ethical-political fundamental principles of the information and communication technologies. By knowing the process in which this evolution started and its following development, considering its constituents, its working procedures and with whom it is developed, its consequences and implications, can positively contribute to raise, in the learner, consciousness for using these resources. It also creates an audience that does not exist when using other means.

The school and education relation-comprehended as "mediation that takes place among the social practices" -with the communication means, need to go beyond the formation of the critical receptor as it occurs, currently, at homes or in all the places where people live or work with these technologies. The relation of the school and education with the information and communication technologies needs to be based on the awareness of developing a discerning relation in the user with the communication mean.

In this way, the compromise and the pedagogical work need to overcome the usage of these means as auxiliary resources for the teaching process, observing its purposes that is frequently fulfilled with the change of the "representation" for the "capability", underusing the unexpected potential of the representation chosen and distorting the reality intended to focus.

Known as a resource, due to the theoretical-methodological and ethical-political basic principles, the information and communication technologies can become a valuable pedagogical resource for an integral formation of children and adolescents, and also for the continuing formation of adults and professionals.

These information and communication technologies are valuable resources for networking environments and communications among teachers, giving the possibility to update themselves, share experiences, create informative materials and theoretical improvements altogether. Researches and tangible experiences proved that the role of teachers in Higher Education and their networking discourse contribute in the creation of more symmetrical relations than the ones from a traditional educational context, since they work in a wider universe of data and information. Therefore, their communication occurs, consequently, in a more competent and wider way.

For this reason, when used in a wise way and for the specific purpose of its creation and development, the information and communication technologies are contributing for the evolution of knowledge and humanity. 


\section{Conclusions}

The usage of Information and Communication Technologies in Higher Education establishes a new way of coexisting with a world that strives to become more human, demanding new means of intervention to create more humanized relations.

Technology takes part in the development of the human history. With this in mind, technology takes part in the cultural heritage of society conjunct. It is, contradictorily, an element of power, of social control, of domination, not only from central or peripheral countries, as well as inside the teaching institutions and in the conjunct of the society. It is established for social conditions, collective strength, cultural traditions and political options.

Culture, in its anthropological sense, is understood as a conjunct of meanings or intellectual, ethical, esthetical, social, technical, mythical, behavioral types of information that characterize a social group [8].

We can only understand and work the technological productions with this historical-political and social-historical comprehension. According to this thought, [9] argue that:

Communication Technologies are implements in which man builds the representation and, therefore, it is mentally incorporated later on, becoming internalized. Hence, considering our thought systems the creation of this internalized mediation process developed by/in our culture.

It is important to reinforce the dimension of citizen's education inside universities and in society. For this, it is necessary to combine all the technologies in the framework of educational goals regarding the political, ethical, social, pedagogical and didactical dimensions. Moreover, developing our criticism strength and relative autonomy, revaluing the learning process productions, taking into consideration that these productions are not apart from the knowledge and power relations inside educational institutions, reinforcing the ideas of conceiving, creating, making and thinking about the process and, also, valorizing the production and the product as well.

The human formation of professionals of education, or any other professional, inside universities needs to incorporate all scientific and technological progress developed by men for the good of all human kind. Therefore, not only the technical instruments are needed, but also the purposes and the ethical-political compromises to socialize knowledge and information in order to humanize the world.

Actually, this real technology is the frame to create competent and qualified professionals for the exercise of good citizenship. Since the usage of the information and communication in education as a pedagogical resource can not only be classified as necessary, but also considered as a valuable "support" in the formation of critical and creative thoughts when the apprentice takes ownership of the theoretical-methodological and ethical-political basic principles of the information and communication technologies.

\section{References}

[1] Ianni, O. (1999) The world of work. In: Freitas, M.C., Ed., The future reinvention (2nd Edition) (In Portuguese) Cortez, São Paulo.

[2] Harvey, D. (1992) The condition of postmodernity (In Portuguese). Loyola, São Paulo.

[3] Kuenzer, A. (1999) The formation policies: Constitution of a residual teacher identity. Education \& Society (In Portuguese), 20, 163-183. http://dx.doi.org/10.1590/S0101-73301999000300009

[4] Ferreira, N.S.C. (1998) Education technology and the professional in Brazil: His or her formation and the possibility of human culture. Educational Technology Magazine (In Portuguese), 26, 141.

[5] Bourdieu, P. (1997) On television (In Spanish). Anagrama Editorial, Barcelona.

[6] Ferreira, N.S.C. (1999) Education technology and the professional in Brazil: His or her formation and the possibility of human culture. Bulletin of Science, Technology \& Society, 19, 206-209. Sage Science Press, Thousand Oaks, London, New Delhi. http://dx.doi.org/10.1177/027046769901900304

[7] Apple, M. (1989) Teachers and Texts (In Spanish). Paidós/MEC, Barcelona.

[8] Sacristán, G.J. (1994) Dilemmas and options. In Pedagogy's Notebooks (In Spanish). 225, Madrid, 8-14.

[9] Coll, C., Palácios, J. and Marchesi, A. (1995) Psychological development and education: Special educative necessities and school education (In Portuguese). Artes Médicas, Porto Alegre. 